\title{
Association of Depression with Healihy Eating practice among diabetic and non diahetic eases in Kolkata, India
}

\section{T khatun1, D Mukharjee², A Hoque1, TK Biswas3 \\ ${ }^{1}$ Faculty of Public Health, Dept of Community Nutrition, Bangladesh University of Health Sciences \\ (BUHS), Bangladesh; 2Quality Manager, West Bengal Govt. District Hospital, Purulia, India; ${ }^{2}$ Lecturer cum visiting physician, Dept of international medicine, State ayurvedic Medical College and Hospital; India.}

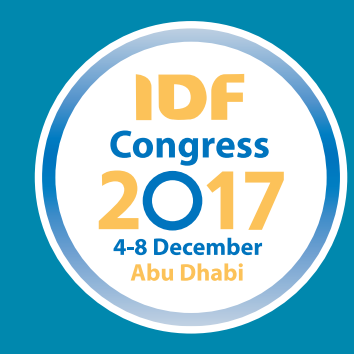

Email: tasumoni11@yahoo.com

\section{Background}

Depression level and poor dietary practice are independently associated with poor glycemic control in subjects with type 2 diabetes (T2D); however, the relationship between them is still ambiguous.

\section{Aim}

To determine the association between dietary quality and symptoms of depression among diabetic and non diabetic Indians living in Kolkata

\section{Material and Methods}

In this cross sectional analytical study total 510 subjects along with 155 diabetes mellitus (DM) subjects and 355 healthy non diabetes mellitus (NDM) subjects were studied purposively. The subjects of DM and NDM were collected from Department of Internal Medicine, J. B. Roy State Ayurvedic Medical College \& Hospital, Kolkata. Face to face interview was done. Study subjects were determined by a $24 \mathrm{hr}$ recall method questionnaire and food intake pattern was measured by a specific food frequency questionnaire (FFQ) for 30 days. Quality of diet was determined using the Healthy Eating Index-2010 (HEl-10) score. The HEI-2010 comprises 12 components that sum to a maximum total score of 100 . Symptoms of depression were assessed using the Beck Depression Inventory (BDI). Data was analyzed with univariate and multivariate techniques by using SPSS18.0 for windows.

\section{Results}

- Age (years) $\mathrm{M} \pm \mathrm{SD}$ of the study subjects were $50.25 \pm 9.52$ (non-diabetic) and $50.03 \pm 9.65$ (diabetic). Comparison between anthropometric characteristics of nondiabetic and diabetic cases. Height and weight among non diabetic patients was respectively $158 \pm 10.25$ and $56.56 \pm$ 8.14 in comparison with $158 \pm 10.51$ and $56.58 \pm 7.90$ among diabetic patients. Other variables like Body mass index (BMI), Waist circumference (WC), Hip circumference $(\mathrm{HC})$ of the subjects were approximately same in both groups. No significant difference was found in any variable.(Table1)

- The majority of the diabetic subjects were $(57.4 \%)$ extreme depressed, where rest of the subjects were either moderate depressed $(16.1 \%)$ or severe depressed (26.5\%) according to Beck Depression Inventory Scale. Significant difference was found in DM and NDM subjects $(<0.001)$. On the other hand the majority of the nondiabetic subjects were $(40.6 \%)$ severe depressed, where rest of the subjects were either normal ups and downs $(11.3 \%)$, mild mood distrubed (9.9\%), borderlined clinical depressed(3.7\%) or moderate depressed (16.6\%) in and $18.0 \%$ had extreme depressed according to Beck Depression Inventory Scale. (Table 2)

- Healthy Eating Index Scores-10 (HEl-10) among nondiabetic patients was $42.88 \pm 7.88$ in comparison with $31.87 \pm 8.62$ among diabetic patients $(p<0.001)$ and BDI score among non diabetic patients was $29.85 \pm 14.85$ in compare with $41.59 \pm 9.36$ with T2DM subjects (<0.001).(Table 3 )

- Comparison of Healthy eating index scores-2010 components and scoring standards among nondiabetic and diabetic patients. Significant difference was found in Total Vegetables where 'Standard for maximum score' was $100 \%$ for non-diabetic and $85.8 \%$ for diabetic cases $(p=<0.001$ ), in Whole Greens and Beans where 'Standard for maximum score' was $100 \%$ for non-diabetic and $91.6 \%$ for diabetic cases $(p=<0.001)$, in Refine Grains where 'Standard for minimum score' was $100 \%$ for diabetic cases and $3.4 \%$ for non-diabetic cases $(p=<0.001)$. (Table 4$)$

Table 1: Anthropometric characteristics of diabetic and nondiabetic cases (510)

\begin{tabular}{lccc} 
Variables & $\begin{array}{c}\text { Nondiabetic } \\
(\mathrm{n}=355)\end{array}$ & $\begin{array}{c}\text { Diabetic } \\
(\mathrm{n}=155)\end{array}$ & P-value \\
\hline Age $($ years $)$ & $50.25 \pm 9.52$ & $50.03 \pm 7.96$ & 0.281 \\
Height $(\mathrm{cm})$ & $158.63 \pm 10.25$ & $158.63 \pm 10.51$ & 0.875 \\
Weight $(\mathrm{Kg})$ & $56.56 \pm 8.14$ & $56.58 \pm 7.90$ & 0.988 \\
Body Mass Index $(\mathrm{BMI})(\mathrm{Kg} /)$ & $22.59 \pm 3.14$ & $22.58 \pm 3.22$ & 0.971 \\
Waist Circumference $(\mathrm{WC})$ & $81.78 \pm 4.99$ & $81.75 \pm 4.52$ & 0.942 \\
Hip Circumference $(\mathrm{HC})$ & $88.80 \pm 5.91$ & $88.13 \pm 5.76$ & 0.234 \\
Comparison done by test for categorical variables, $p$-value $<0.05$ was considered statistically significant \\
\hline
\end{tabular}

Table 2: Clinical depression among Non-diabetic and diabetic Patients

\begin{tabular}{lccc} 
Classifications & $\begin{array}{c}\text { Nondiabetic } \\
(\mathrm{n}=355)\end{array}$ & $\begin{array}{c}\text { Diabetic } \\
(\mathrm{n}=155)\end{array}$ & P-value \\
\hline Normal ups \& downs & $40(11.3 \%)$ & $0(0 \%)$ & \\
Mild mood disturbance & $35(9.9 \%)$ & $0(0 \%)$ & \\
Borderline clinical depression & $13(3.7 \%)$ & $0(0 \%)$ & $<0.001$ \\
Moderate depression & $59(16.6 \%)$ & $25(16.1 \%)$ & \\
Severe depression & $144(40.6 \%)$ & $41(26.5 \%)$ & \\
\hline Extreme depression & $64(18.0 \%)$ & $89(57.4 \%)$ & \\
\hline
\end{tabular}

Table 3: Comparison of HEIS-10 and BDI score among nondiabetic and diabetic Subjects

\begin{tabular}{lccc} 
Categories & $\begin{array}{c}\text { Nondiabetic } \\
(\mathrm{n}=355)\end{array}$ & $\begin{array}{c}\text { Diabetic } \\
(\mathrm{n}=155)\end{array}$ & P-value \\
\hline Healthy Eating Index Scores- 10 & $42.88 \pm 7.88$ & $31.87 \pm 8.62$ & $<0.001$ \\
\hline Depression (BDI) score & $29.85 \pm 14.85$ & $41.59 \pm 9.36$ & \\
Comparison done by chi-square test for categorical variables, $p$-value $<0.05$ was considered statistically significant
\end{tabular}

Table 4: Healthy eating index socres-2010 components and scoring standards among nondiabetic and diabetic subjects

\begin{tabular}{|c|c|c|c|}
\hline Food Groups & Nondiabetic $(n=355)$ & Diabetic $(n=155)$ & P-value \\
\hline \multicolumn{4}{|l|}{ Whole Fruits } \\
\hline Standard for minimum score & $271(76.3 \%)$ & $120(77.4 \%)$ & \multirow{2}{*}{0.791} \\
\hline Standard for maximum score & $84(23.7 \%)$ & $35(22.6 \%)$ & \\
\hline \multicolumn{4}{|l|}{ Total Fruits } \\
\hline Standard for minimum score & $338(95.2 \%)$ & $147(94.8 \%)$ & \multirow{2}{*}{0.858} \\
\hline Standard for maximum score & $17(4.8 \%)$ & $8(5.2 \%)$ & \\
\hline \multicolumn{4}{|l|}{ Total Vegetables } \\
\hline Standard for minimum score & $0(0 \%)$ & $22(14.2 \%)$ & \multirow{2}{*}{$<0.001$} \\
\hline Standard for maximum score & $355(100 \%)$ & $133(85.8 \%)$ & \\
\hline \multicolumn{4}{|l|}{ Greens and Beans } \\
\hline Standard for minimum score & $23(6.5 \%)$ & $17(11.0 \%)$ & \multirow{2}{*}{0.083} \\
\hline Standard for maximum score & 332 (93.5\%) & $138(89.0 \%)$ & \\
\hline \multicolumn{4}{|l|}{ Whole Greens and Beans } \\
\hline Standard for minimum score & $0(0 \%)$ & $13(8.4 \%)$ & \multirow{2}{*}{$<0.001$} \\
\hline Standard for maximum score & $355(100 \%)$ & $142(91.6 \%)$ & \\
\hline \multicolumn{4}{|l|}{ Dairy } \\
\hline Standard for minimum score & $163(45.9 \%)$ & $71(45.8 \%)$ & \multirow{2}{*}{0.982} \\
\hline Standard for maximum score & $192(54.1 \%)$ & $84(54.2 \%)$ & \\
\hline \multicolumn{4}{|l|}{ Total Protein Foods } \\
\hline Standard for minimum score & $299(84.4 \%)$ & $114(73.5 \%)$ & \multirow{2}{*}{0.005} \\
\hline Standard for maximum score & $56(15.8 \%)$ & $41(26.5 \%)$ & \\
\hline \multicolumn{4}{|l|}{ Sea Food and Plant Proteins } \\
\hline Standard for minimum score & $345(97.2 \%)$ & $152(98.1 \%)$ & \multirow{2}{*}{0.561} \\
\hline Standard for maximum score & $10(2.8 \%)$ & $3(1.9 \%)$ & \\
\hline \multicolumn{4}{|l|}{ Fatty Acids } \\
\hline Standard for minimum score & $355(100 \%)$ & $155(100 \%)$ & - \\
\hline \multicolumn{4}{|l|}{ Refine Grains } \\
\hline Standard for minimum score & $12(3.4 \%)$ & $155(100 \%)$ & \multirow{2}{*}{$<0.001$} \\
\hline Standard for maximum score & $343(96.6 \%)$ & $0(0 \%)$ & \\
\hline \multicolumn{4}{|l|}{ Sodium } \\
\hline Standard for minimum score & $348(98.0 \%)$ & $150(96.8 \%)$ & \multirow{2}{*}{0.390} \\
\hline Standard for maximum score & $7(2.0 \%)$ & $5(3.2 \%)$ & \\
\hline \multicolumn{4}{|l|}{ Empty Calories } \\
\hline Standard for minimum score & $10(2.8 \%)$ & $7(4.5 \%)$ & \\
\hline Standard for moderate score & $211(59.4 \%)$ & $99(63.9 \%)$ & 0.346 \\
\hline Standard for maximum score & & & \\
\hline
\end{tabular}

\section{Conclusions}

Diabetic depressed people are living in Kolkata with low quality of dietary intake. Symptoms of depression are higher among diabetic cases, where healthy eating index scores were higher among non diabetic subjects. For both issues hereby needed comprehensive intervention. 